\title{
A 4-year review of pediatric mental health emergencies in Alberta
}

\author{
Amanda S. Newton, PhD, RN; ${ }^{* \dagger}$ Samina Ali, MD; ${ }^{*}$ David W. Johnson, MD; ${ }^{\ddagger}$ Christina Haines, MSc; ${ }^{* \dagger}$ \\ Rhonda J. Rosychuk, PhD; ${ }^{* \dagger}$ Rachel A. Keaschuk, PsyD; ${ }^{\S}$ Philip Jacobs, PhD; ${ }^{\pi}$ Terry P. Klassen, MSc, MD*
}

\section{ABSTRACT}

Objective: We sought to determine and compare rates of pediatric mental health presentations and associated costs in emergency departments (EDs) in Alberta.

Methods: We examined 16154 presentations by 12589 patients (patient age $\leq 17 \mathrm{yr}$ ) between April 2002 and March 2006 using the Ambulatory Care Classification System, a province-wide database for Alberta. The following variables of interest were extracted: patient demographics, discharge diagnoses, triage level, disposition, recorded costs for ED care, and institutional classification and location (i.e., rural v. urban, pediatric v. general EDs).

Results: A $15 \%$ increase in pediatric mental health presentations was observed during the study period. Youth aged 1317 years consistently represented the most common age group for first presentation to the ED (83.3\%). Of the 16154 recorded presentations, $21.4 \%$ were related to mood disorders and $32.5 \%$ to anxiety disorders. Presentations for substance misuse or abuse were the most prevalent reasons for a mental health-related visit (41.3\%). Multiple visits accounted for more than one-third of all presentations. Presentations for mood disorders were more common in patients with multiple compared with single visits ( $29.3 \%$ v. $16.9 \%)$, and substance abuse or misuse presentations were more common in patients with single compared with multiple visits $(47.4 \%$ v. $30.5 \%)$. The total direct ED costs for mental health presentations during the study period was Can $\$ 3.5$ million.

Conclusion: This study provides comprehensive data on trends of pediatric mental health presentation, and highlights the costs and return presentations in this population. Psychiatric and medical care provided in the ED for pediatric mental health emergencies should be evaluated to determine quality of care and its relationship with return visits and costs.

Keywords: pediatrics, mental health, crisis visits, emergency

\section{RÉSUMÉ}

Objectif : Nous avons cherché à déterminer et à comparer les taux de consultation pour troubles de santé mentale chez les enfants et les coûts connexes dans les services d'urgence de l'Alberta.

Méthodes : Nous avons analysé 16154 consultations faites par 12589 patients (âge des patients $\leq 17$ ans) entre avril 2002 et mars 2006 à l'aide du système de classification des soins ambulatoires, une base de données utilisée dans toute la province de I'Alberta. Nous avons extrait de cette base de données les variables suivantes : données démographiques sur les patients, diagnostic de sortie, niveau de triage, interventions, coûts établis pour les soins à l'urgence, classification et emplacement de l'établissement (c'est-à-dire, rural ou urbain, service d'urgence générale ou pédiatrique).

Résultats : Nous avons observé une augmentation de $15 \%$ des consultations à l'urgence pour troubles de santé mentale chez les enfants au cours de la période de l'étude. Le groupe d'âge des 13 à 17 ans affichait la plus haute fréquence de première consultation à I'urgence (83,3 \%). Parmi les 16154 consultations consignées, le motif de consultation de $21,4 \%$ était lié à des troubles de I'humeur, et $32,5 \%$, à des troubles anxieux. Les motifs les plus fréquents de consultation liée à des troubles de santé mentale étaient le mésusage ou l'abus de substances psychoactives (41,3\%). Des visites multiples représentaient plus d'un tiers de toutes les consultations. Les troubles de I'humeur étaient un motif plus fréquent chez les patients ayant effectué de multiples visites par rapport à ceux qui n'en avaient fait qu'une $(29,3 \%$ contre $16,9 \%)$, et l'abus ou le mésusage de substances psychoactives était un motif de visite plus fréquent chez les patients ayant effectué une seule visite par rapport à ceux qui en avaient fait plusieurs (47,4\% contre 30,5\%). Les coûts directs aux services d'urgence liés aux consultations pour troubles de santé mentale au cours de la période de l'étude s'élevaient à 3,5 millions de dollars canadiens.

From the *Department of Pediatrics, Faculty of Medicine and Dentistry, University of Alberta, Edmonton, Alta., tWomen and Children's Health Research Institute, Edmonton, Alta., the $¥$ Departments of Pediatrics and Pharmacology \& Therapeutics, Faculty of Medicine, University of Calgary, Calgary, Alta., §Pediatric Centre for Weight and Health, Stollery Children's Hospital, Edmonton, Alta., and ๆlnstitute of Health Economics, Edmonton, Alta.

Submitted Sep. 16, 2008; Revised Feb. 24, 2009; Accepted Feb. 28, 2009

This article has been peer reviewed.

CJEM 2009;11(5):447-54 
Conclusion : Cette étude fournit des données détaillées sur les tendances relatives aux consultations à l'urgence pour troubles de santé mentale chez les enfants. Elle met aussi en évidence les coûts et les motifs de visites multiples auprès de cette popu- lation. Les soins psychiatriques et médicaux fournis à l'urgence pour des troubles de santé mentale chez les enfants devraient faire l'objet d'une évaluation afin de déterminer leur qualité et leur rapport avec les visites subséquentes et les coûts.

\section{INTRODUCTION}

The demand for mental health care services in the emergency department (ED) is increasing. Emergency departments are an entry point for families to access crisis care ${ }^{1-6}$ and are considered a "safety net" in response to the lack of other psychiatric services. ${ }^{8,9}$ Although approximately $15 \%$ of Canadian children and youth live with a mental illness, ${ }^{10}$ as few as 1 in 6 children and youth receive necessary mental health care services, ${ }^{11,12}$ leaving those who are untreated vulnerable to acute crises and in need of ad hoc support.

American studies reporting ED visits for pediatric mental health concerns cite varied presentation rates at single urban sites with reports ranging from 3\%-5\% ${ }^{1,2}$ up to $25 \%,{ }^{13}$ and national statistics estimated at $1.6 \% .^{14}$ Although these studies have demonstrated important trends in access to the health care system, to our knowledge such comprehensive data have never been reported for Canadian EDs. Moreover, published works have yet to report trends in ED costs for emergency mental health care. We aimed to determine the presentation rates for ED visits related to mental health in Alberta, and to describe the costs of the use of health care services for these visits.

\section{METHODS}

\section{Design}

Data collected during 4 fiscal years (April 2002 to March 2006) were obtained from the Ambulatory Care Classification System (ACCS), a database established in 1997 by Alberta Health and Wellness to house all ambulatory care data including data from Alberta's EDs. The database is linked with a provincial registry to provide patient-specific information, such as demographics and socioeconomic features. The protocol for this study was approved by our research ethics board.

\section{Study population}

To generate provincial estimates of ED mental healthrelated visits for pediatric patients (patient age $\leq 17 \mathrm{yr}$ ), we included only patients who were assigned a main ambulatory care diagnosis using the International Statistical Classification of Diseases and Related Health Problems Canadian version (ICD-10-CA) ${ }^{15}$ for mental illness (F20-F25, F28-29, F30-F34, F38-F39, F40-F43, F50, F55, F59), substance misuse or abuse (F10-F19, T51T52, T58-T59) or intentional self-harm (T71, X60 X84). Each patient record in the database was identified by a unique identifier, linking the record to age, sex and socioeconomic features. The database also houses information related to care including patient-specific costs. ${ }^{16}$

\section{Data collection}

Visit data were collected for each ED presentation and included triage level (coded according to the Canadian Emergency Department Triage and Acuity Scale [CTAS] $)^{17,18}$ and disposition status to identify visit outcomes. Using ACCS intervention (grouper) cells, costing data were collected for each patient by fiscal year: estimated costs for health care provider services, time taken for care, resources consumed (in terms of diagnostics/ supplies/drugs) and other ancillary costs for providing care in the ED. These cost data were used to classify each patient into groups with similar resource needs and clinical profiles. Institutions were classified as rural versus urban, and pediatric versus general EDs. Urban areas met the Statistics Canada definition of census metropolitan area or census agglomeration, namely, an urban core population greater than 10000 including all neighbouring municipalities, for which at least one-half of the labour force commutes to the urban core. ${ }^{19}$ Pediatric ED facilities were those in an identified pediatric hospital. Demographic data included age at each ED presentation, sex and socioeconomic status. Children and youth living in Alberta with a "Band Indian" identifier, that is, an identifier of Native band membership in Alberta, were identified. ${ }^{20}$ No other ethnic or cultural group was recorded in the ACCS database or provincial registry. The level of government support for individual health care payments as recorded in the provincial registry was used as a proxy measure of socioeconomic status. Albertans with lower incomes or receiving social services receive either full or partial coverage of provincial health care premiums. 


\section{Data analyses}

Categorical variables are shown by main ambulatory diagnosis and fiscal year. We tested for a statistical relationship between individual patient and fiscal year using an unordered $\chi^{2}$ test of independence. We did not test for a relationship between fiscal year and characteristics related to the ED visit because of the substantial number of multiple presentations made by the same child or youth. Because cost data were highly skewed, median costs per presentation as well as total accumulated costs by individual are reported by main ambulatory diagnosis and fiscal year. Two-way analysis of variance was used to test for a statistical relationship between total accumulated cost with diagnosis and fiscal year. A 0.05 significance level was used for all testing. Data were analyzed using S-Plus software (S-Plus 8.0 for Windows, Insightful Corp.).

Table 1. Pediatric mental health presentations to emergency departments in Alberta (fiscal 2003 to 2006)

\begin{tabular}{lccc}
\hline Fiscal year & $\begin{array}{c}\text { No. of } \\
\text { pediatric ED } \\
\text { presentations }\end{array}$ & $\begin{array}{c}\text { No. of visits } \\
\text { (\% of total ED } \\
\text { presentations) }\end{array}$ & $\begin{array}{c}\text { No. of } \\
\text { children/ } \\
\text { youth }\end{array}$ \\
\hline $2002 / 03$ & 435073 & $3768(0.87)$ & 3142 \\
$2003 / 04$ & 450563 & $3870(0.86)$ & 3003 \\
$2004 / 05$ & 424369 & $4165(0.98)$ & 3173 \\
$2005 / 06$ & 420446 & $4351(1.00)$ & 3271 \\
\hline ED = emergency department. & & \\
\hline
\end{tabular}

\section{RESULTS}

Children and youth made approximately 1.7 million ED presentations in Alberta between April 2002 and March 2006, based on visit data reported by an average of 98 EDs (Table 1). After we excluded those visits related to "toxic effects of non-medicinal substances" $(n=63)$ and "self-harm" $(n=1)$ that were coded as being accidental or unintentional, there was a total of 16154 visits that were for mental health-related concerns by 12589 children and youth. Patients transferred to another ED for continuation of care are recorded in the ACCS database as having 2 separate ED visits. For our study, we recoded such transfers to another ED within 24 hours $(n=102)$, as a single event to avoid overestimation of the incidence of repeat visits. The number of ED presentations for pediatric mental health needs increased $15 \%$ during the study period, from 3768 in fiscal 2003 to 4351 in fiscal 2006. Overall, the percentage of ED presentations by children and youth attributed to mental health increased from $0.9 \%$ to $1.0 \%$ during the same 4 years. The number of children and youth presenting to the ED with a concern related to mental health increased by $4 \%$, from 3142 to 3271 . The number of presentations per patient per year ranged from 1 to 20 , and increased by $11 \%$ from an average of 1.12 to 1.33 .

Significant heterogeneity was noted for main ambulatory diagnoses of children and youth (Fig. 1). Across the study period, mental and behavioural disorders and toxic effects resultant from substance abuse or misuse

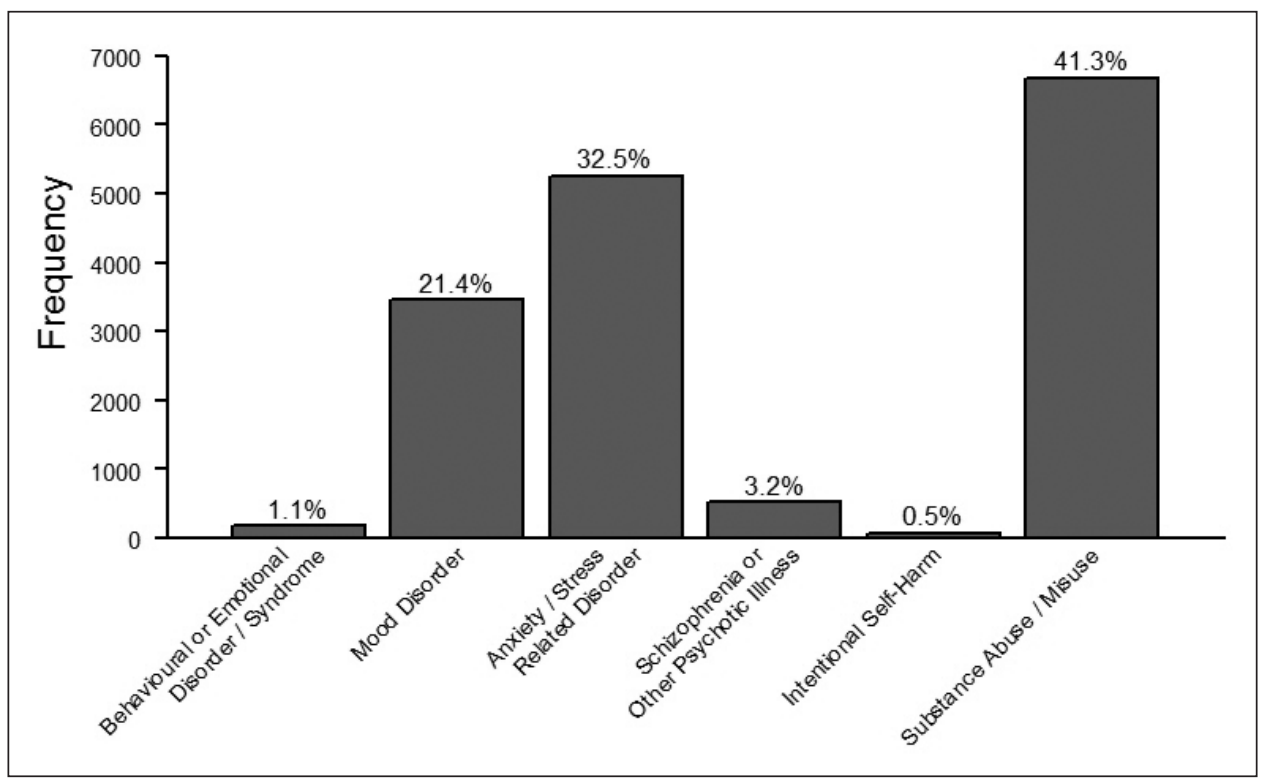

Fig. 1. Primary mental health diagnostic code for children or youth attending emergency departments in Alberta (fiscal 2003 to 2006). 
were the most frequently diagnosed in the 16154 presentations ( $n=6675,41.3 \%)$, and chronic disorders such as anxiety $(n=5254,32.5 \%)$ and mood disorders $(n=3455,21.4 \%)$ were also common. Intentional selfharm, on the other hand, represented very few of ED presentations $(n=73,0.5 \%)$. Most secondary diagnoses were also related to mental health $(51.3 \%)$, and accidents and injuries were diagnosed in $30.1 \%$ of children and youth with a primary mental health concern. Physical illness or disease as a secondary diagnosis was diagnosed in $17.4 \%$ of children and youth.

\section{Patient characteristics}

There was heterogeneity in the number of presentations per fiscal year, which also varied by year $(p=0.001)$ (Table 2). An association was also noted between the year and the age group at first presentation. The number of presentations for children aged $0-5$ years decreased, and presentations by children aged 6-12 years and youth aged 13-17 years varied but increased overall. Youth aged 13-17 years consistently represented the most common group for first presentation to the ED. Although more girls were seen in the ED for emergency mental health concerns, the proportion by sex remained stable. Most of the children and youth who visited the ED were from families not receiving any form of social assistance. A small percentage of children and youth were of Aboriginal status, although the ethnicity of those without declaration could not be determined. There was no relationship observed between the year of presentation and the declared Aboriginal status $(p=0.51)$ or socioeconomic status $(p=0.31)$.

\section{Visit characteristics}

Most presentations took place in urban regions $(66.7 \%)$ and general EDs (87.4\%) (Table 3). There was a substantial amount of missing CTAS data (ranging from $51 \%$ in fiscal 2003 to $15 \%$ in fiscal 2006 , mean $27 \%$ overall), as triage scores are not mandated for provincial reporting. Based on this significant underreporting, we were unable to assess trends in prioritization of presentations. The majority of mental health presentations resulted in discharge $(83.8 \%)$ during the study period. A $610 \%$ increase in the number of presentations in which the child or youth left either without being seen or against medical advice was noted from fiscal 2003 $(n=24)$ to $2006(n=147)$. The absolute proportion of presentations for mental and behavioural disorders due to substance abuse or misuse increased by $5 \%$, and for toxic effects from substance abuse or misuse by $2 \%$ during the study. However, the total number of presentations for these diagnostic groups was much more substantial. During the study period there was a $36 \%$ increase in mental and behavioural disorders due to

\begin{tabular}{|c|c|c|c|c|c|c|}
\hline \multirow[b]{2}{*}{ Characteristic } & \multicolumn{5}{|c|}{ Fiscal year; no. (\%) of children/youth } & \multirow[b]{2}{*}{$p$ value } \\
\hline & $2002 / 03$ & $2003 / 04$ & $2004 / 05$ & $2005 / 06$ & Total & \\
\hline Total no. of children/youth & 3142 & 3003 & 3173 & 3271 & 12589 & $0.001^{*}$ \\
\hline Age group at first presentation, $\mathrm{yr}$ & & & & & & $0.02 *$ \\
\hline $0-5$ & $174(5.5)$ & $156 \quad(5.2)$ & 143 & $137 \quad(4.2)$ & 610 (4.9) & \\
\hline $6-12$ & $360(11.5)$ & 327 (10.9) & $380(12.0)$ & $429(13.1)$ & 1496 (11.9) & \\
\hline $13-17$ & $2608(83.0)$ & $2520(83.9)$ & $2650(83.5)$ & $2705(82.7)$ & 10483 (83.3) & \\
\hline Sex & & & & & & $0.05^{*}$ \\
\hline Male & $1302(41.4)$ & $1341(44.7)$ & $1405(44.3)$ & $1424(43.5)$ & 5472 (43.5) & \\
\hline Female & $1840(58.6)$ & $1662(55.3)$ & $1768(55.7)$ & $1847(56.5)$ & $7117(56.5)$ & \\
\hline Aboriginal status & & & & & & 0.51 \\
\hline Declared & $392(12.5)$ & $400(13.3)$ & $433(13.6)$ & $443(13.5)$ & $1668(13.2)$ & \\
\hline Undeclared & $2750(87.5)$ & $2603(86.7)$ & $2740(86.4)$ & $2828(86.5)$ & 10921 (86.8) & \\
\hline pSES & & & & & & 0.31 \\
\hline Full premium arrangement & $392(12.5)$ & 400 (13.3) & $433(13.6)$ & $443(13.5)$ & $1668(13.2)$ & \\
\hline Welfare & $193(6.1)$ & 160 & $170 \quad(5.4)$ & 151 & $674 \quad(5.4)$ & \\
\hline Government sponsored program & $455(14.5)$ & $450(15.0)$ & $486(15.3)$ & $505(15.4)$ & $1896(15.1)$ & \\
\hline Regular plan participant & $2102(66.9)$ & $1993(66.4)$ & $2084(65.7)$ & $2172(66.4)$ & 8351 (66.3) & \\
\hline
\end{tabular}


substance abuse or misuse and a 35\% increase for toxic effects from substance abuse or misuse. Presentations in all other diagnostic categories decreased slightly (range $4 \%$ [mood disorders] to $25 \%$ [self-harm]).

\section{Characteristics of single versus multiple pediatric mental health ED presentations}

Table 4 provides presentation characteristics for children and youth with one ED presentation compared with children and youth who made multiple presentations. Of the 16154 mental health presentations during the study period, 10305 (63.8\%) were made by children and youth with one visit. There were minimal differences between the region and type of ED where single versus multiple presentations occurred. A repeat visit was more likely to end in admission (17.4\%) than a single presentation (9.5\%). Mental and behavioural disorders and toxic effects resulting from substance abuse or misuse were more frequently diagnosed in patients with a single ED visit (47.4\% compared with $30.5 \%$ ) and mood disorders were more frequently diagnosed in patients with multiple ED presentations $(29.3 \%$ compared with $16.9 \%$ ) as were schizophrenia and other psychotic illnesses (5.8\% compared with $1.8 \%$ ).

\section{Economic costs}

During the study period, the total direct costs for mental health presentations was Can\$3.5 million. Table 5 shows that this total cost increased during the study period, from approximately three-quarters of a million dollars (\$761 633.80) in fiscal 2003 to just over \$1 million in fiscal 2006 (\$1 011 673.21). Presentations related to mental and behavioural disorders due to substance abuse or misuse contributed $37.9 \%$ to this total cost, and intentional self-harm contributed the least $(0.8 \%)$. There was a significant relationship between total cost and diagnosis $(p<0.001)$ and fiscal year $(p=$ $0.019)$. Across all fiscal years combined, the median cost per presentation was greatest for those children and youth presenting with intentional self-harm (\$348.70). Presentations for both mood disorders and anxiety/stress-related disorders had the lowest median

\begin{tabular}{|c|c|c|c|c|c|}
\hline \multirow[b]{2}{*}{ Characteristic } & \multicolumn{5}{|c|}{ Fiscal year; no. (\%) of presentations* } \\
\hline & $\begin{array}{l}2002 / 03 \\
n=3768\end{array}$ & $\begin{array}{l}2003 / 04 \\
n=3870\end{array}$ & $\begin{array}{l}2004 / 05 \\
n=4165\end{array}$ & $\begin{array}{l}2005 / 06 \\
n=4351\end{array}$ & $\begin{array}{c}\text { Total, } \\
n=16154\end{array}$ \\
\hline Median no. of presentations per child/youth (range) & $1(1-13)$ & $1(1-19)$ & $1(1-7)$ & $1(1-14)$ & $1(1-19)$ \\
\hline \multicolumn{6}{|l|}{ Region } \\
\hline Urban & $2509(66.6)$ & $2602(67.2)$ & $2770(66.5)$ & $2887(66.4)$ & $10768(66.7)$ \\
\hline Rural & 1259 (33.4) & $1268(32.8)$ & $1395(33.5)$ & 1464 (33.6) & 5386 (33.3) \\
\hline \multicolumn{6}{|l|}{ ED classification } \\
\hline Pediatric & $421(11.2)$ & $476(12.3)$ & $545(13.0)$ & $591(13.6)$ & $2033(12.6)$ \\
\hline General & 3347 (88.8) & $3394(87.7)$ & $3620(86.9)$ & $3760(86.4)$ & $14121(87.4)$ \\
\hline \multicolumn{6}{|l|}{ Disposition } \\
\hline Discharge & 3158 (83.8) & 3259 (84.2) & 3469 (83.3) & $3655(84.0)$ & $13541(83.8)$ \\
\hline Admission & $509(13.5)$ & $512(13.2)$ & $500(12.0)$ & 475 (10.9) & $1996(12.4)$ \\
\hline Transfer & $77 \quad(2.0)$ & 73 (1.9) & 81 (1.9) & $70(1.6)$ & 301 (1.9) \\
\hline Left $†$ & $24 \quad(0.6)$ & $24 \quad(0.6)$ & $113 \quad(2.7)$ & 147 (3.4) & 308 (1.9) \\
\hline Died & $0 \quad(0.0)$ & $2(0.1)$ & $2(0.0)$ & $4 \quad(0.1)$ & $8(0.1)$ \\
\hline \multicolumn{6}{|l|}{ Main ambulatory diagnosis (ICD-10-CA) } \\
\hline Behavioural or emotional disorder/syndrome & $46 \quad(1.2)$ & $44 \quad(1.1)$ & $47 \quad(1.1)$ & $41(0.9)$ & 178 (1.1) \\
\hline Mental/behavioural disorder due to substance abuse & 1014 (26.9) & 1181 (30.5) & $1323(31.8)$ & $1378(31.7)$ & $4896(30.3)$ \\
\hline Mood disorder & $870(23.1)$ & $857(22.1)$ & $895(21.5)$ & $833(19.1)$ & $3455(21.4)$ \\
\hline Anxiety/stress-related disorder & 1259 (33.4) & $1241(32.1)$ & $1346(32.3)$ & $1408(32.4)$ & 5254 (32.5) \\
\hline Schizophrenia or other psychotic illness & $155 \quad(4.1)$ & $121 \quad(3.1)$ & $114 \quad(2.7)$ & $129(3.0)$ & 519 (3.2) \\
\hline Intentional self-harm & $20 \quad(0.5)$ & $17 \quad(0.4)$ & $21 \quad(0.5)$ & $15(0.3)$ & $73 \quad(0.5)$ \\
\hline Toxic effects of nonmedicinal substances & $404(10.7)$ & $409(10.6)$ & $419(10.1)$ & $547(12.6)$ & $1779(11.0)$ \\
\hline
\end{tabular}


cost per presentation of $\$ 125.96$ across all fiscal years combined.

\section{DISCUSSION}

Between April 2002 and March 2006, there were notable increases in pediatric visits related to mental health at Alberta's EDs. Alongside this trend was a shift in patient characteristics. Stereotypes for mental health emergencies typically conjure images of children and youth with injuries from self-harm and acute psychotic episodes. In our sample, however, diagnoses related to these mental health needs accounted for less than $4 \%$ of all presentations. Instead, increases were attributable to patients in need of acute care for substance abuse or misuse and affective (mood, anxiety) disorders. Although rate increases noted in our study likely reflect a number of factors including increasing population base in the province and the lack of resources elsewhere in the community, the

\begin{tabular}{|c|c|c|}
\hline \multicolumn{3}{|c|}{$\begin{array}{l}\text { Table 4. Characteristics of a single versus multiple pediatric } \\
\text { mental health presentations }(n=16154)\end{array}$} \\
\hline \multirow[b]{2}{*}{ Characteristic } & \multicolumn{2}{|c|}{ No. (\%) of presentations } \\
\hline & $\begin{array}{l}\text { Single } \\
n=10305\end{array}$ & $\begin{array}{l}\text { Multiple, } \\
n=5849\end{array}$ \\
\hline \multicolumn{3}{|l|}{ Region } \\
\hline Urban & $6698(65.0)$ & 4070 (69.6) \\
\hline Rural & $3607(35.0)$ & 1779 (30.4) \\
\hline \multicolumn{3}{|l|}{ ED classification } \\
\hline Pediatric & $1446(14.0)$ & $587(10.0)$ \\
\hline General & $8859(86.0)$ & $5262(90.0)$ \\
\hline \multicolumn{3}{|l|}{ Disposition* } \\
\hline Discharge & $9014(87.5)$ & 4527 (77.4) \\
\hline Admission & $980 \quad(9.5)$ & 1016 (17.4) \\
\hline Transfer & $129(1.2)$ & 172 (2.9) \\
\hline Left† & $175(1.7)$ & $133 \quad(2.3)$ \\
\hline Died & $7 \quad(0.1)$ & $1(0.02)$ \\
\hline \multicolumn{3}{|l|}{$\begin{array}{l}\text { Main ambulatory diagnosis } \\
\text { (ICD-10-CA) }\end{array}$} \\
\hline $\begin{array}{l}\text { Behavioural or emotional } \\
\text { disorder/syndrome }\end{array}$ & $113(1.1)$ & $65 \quad(1.1)$ \\
\hline $\begin{array}{l}\text { Mental/behavioural disorder } \\
\text { due to substance abuse }\end{array}$ & 3379 (32.8) & $1517(25.9)$ \\
\hline Mood disorder & 741 (16.9) & 1714 (29.3) \\
\hline Anxiety/stress-related disorder & 3333 (32.3) & 1921 (32.8) \\
\hline $\begin{array}{l}\text { Schizophrenia or other } \\
\text { psychotic illness }\end{array}$ & 182 (1.8) & $337 \quad(5.8)$ \\
\hline Intentional self-harm & $47 \quad(0.5)$ & $26 \quad(0.4)$ \\
\hline $\begin{array}{l}\text { Toxic effects of nonmedicinal } \\
\text { substances }\end{array}$ & $1510(14.6)$ & 269 (4.6) \\
\hline $\begin{array}{l}\text { ED = emergency department. } \\
{ }^{*} \text { Disposition from final site if transferred. } \\
\text { †Against medical advice or without being seen }\end{array}$ & & \\
\hline
\end{tabular}

demand on ED resources is clear and this demand must be addressed. As a beginning, examining emergency care provided for substance abuse and chronic disorders could address the most prevalent emergency mental health presentations and those with the highest return rates. To address goals of delivering effective and efficient ED care, the place of the ED in the continuum of mental health care services (e.g., from community-based care to acute ED care) should be addressed.

As an example, children and youth with substance abuse or misuse problems may present with aggression and need physical resources (e.g., an isolation room, security) to manage their behaviours until acute intoxication has subsided. Appropriate and secure holding spaces with readily available resuscitation equipment are needed to safely care for this clinical population. Given that most children and youth present to general EDs, separate spaces from adults with similar presentations may be needed to promote patient safety and comfort. Treatment of substance abuse or misuse in adults during or after an ED visit has been shown to reduce behaviours $^{21}$ and the number of return visits. ${ }^{22}$ Applying this approach to pediatric care would require a shift from acute intervention based on emergency needs to initiating secondary and tertiary prevention efforts. Involvement of family members and friends who attend the ED with pediatric patients has been shown to increase adherence with follow-up care. ${ }^{23}$ Both approaches merit further evaluation in Canadian EDs for children and youth with substance abuse or misuse presentations.

Our study supports previous experience in that children and youth who present to the ED with emergencies for affective disorders have high rates of return visits. ${ }^{24}$ It is possible that our return rate reflected deficits in the current mental health care system. Communitybased services may not be readily available or accessible. It is also possible that these mental health care services do not adequately meet the patients' needs. The ED can address this latter issue by using the emergency presentation as a time for assessment of community-based needs. A discussion with patients and their families on the events that led up to their ED visit can provide a starting point for recommending follow-up services. Given that ED nursing and physician time is constrained, providing the necessary balance between the emergency medical care and delivering other services is needed to understand and address the crisis. There may be utility in standardizing or broadening the availability of specialized crisis services. A more detailed exploration of this multidisciplinary team approach to ED 
mental health care including dependent, interdependent and independent health care role functions, as well as the role of patients and families, is needed.

The \$3.5 million spent on mental health presentations in Alberta EDs emphasizes the need to invest in improving the ability of EDs to address emergency mental health care with efficiency and effectiveness. Although there is no question that this dollar amount is substantial, the median cost per patient (\$244.51) was modest. Efforts to address efficiency and effectiveness should focus on disposition decision-making and discharge planning to reduce return visits (which contributed to $36 \%$ of the costs) and increase specialization of care received. We were unable to estimate societal costs (time off work, school, etc.) for children, youth and their families as these data were not collected in the ACCS database.

\section{Limitations}

There were some noted limitations in this study. First, one of the original study objectives was to determine trends in use of resources using the Canadian Classification of Health Interventions codes ${ }^{25}$ recorded in the ACCS database. However, these data were largely incomplete. The rate of unrecorded interventions ranged from $57.5 \%$ for intentional self-harm care to $90.4 \%$ for mood-related disorders, and made it difficult to estimate use trends or differences between fiscal years or diagnostic groups. When somatic complaints were the main or first ambulatory diagnoses coded, the visit was not captured as mental health related (e.g., intentional self-harm). These reporting limitations are not unique to this study, but point out important considerations for how mental health presentations are tracked in databases. Finally, we did not collect reference data on all pediatric ED presentations. Although collecting this information was not a part of the objectives of this study, such data would help contextualize the scope of the trends relative to other pediatric presentations.

\section{CONCLUSION}

Pediatric mental health emergencies are prevalent and increasingly result in frequent return visits to the ED, suggesting an opportunity for prevention using community-based services. A substantial and increasing number of unique ED presentations are attributed to substance abuse and misuse. Anxiety/stress disorders are also frequent, as well as mood disorders that furthermore result in increasingly frequent return visits. Future studies are needed to determine whether the return rate reflects a lack of available or appropriate community care. Although the role of the ED within the continuum of mental health care services is not well defined, the psychiatric care provided in the ED to children and youth should be scrutinized to determine its quality and relationship to return visits and costs.

Competing interests: The study reported in this paper was supported by a research grant from the Stollery Children's Hospital Foundation, Edmonton, Alta. Dr. Newton is salary supported by the Canadian Child Health Clinician Scientist Program as a Clinican Scientist. Dr. Rosychuk is salary

Table 5. Economic costs associated with pediatric mental health concerns seen in the emergency department (total cost across all visits)

\begin{tabular}{|c|c|c|c|c|c|}
\hline \multirow[b]{2}{*}{ Diagnosis } & \multicolumn{5}{|c|}{ Fiscal year, total presentation costs (median cost/presentation), Can\$ } \\
\hline & $2002 / 03$ & $2003 / 04$ & $2004 / 05$ & $2005 / 06$ & Total \\
\hline $\begin{array}{l}\text { Behavioural or emotional } \\
\text { disorder/syndrome }\end{array}$ & 8948.16 (135.74) & 8322.89 (125.96) & 10848.19 (123.55) & 10244.20 (123.55) & 38363.44 (135.74) \\
\hline $\begin{array}{l}\text { Mental/behavioural } \\
\text { disorder due to } \\
\text { substance abuse }\end{array}$ & 264345.00 (244.51) & 304252.85 (247.19) & 385529.83 (268.56) & 393096.14 (268.56) & 1347223.84 (268.56) \\
\hline Mood disorder & 156927.78 (135.74) & 156801.83 (125.96) & 200279.83 (123.55) & 182540.49 (123.55) & 696549.94 (125.96) \\
\hline $\begin{array}{l}\text { Anxiety/stress-related } \\
\text { disorder }\end{array}$ & 188730.21 (135.74) & 181186.81 (125.96) & 211406.22 (123.55) & 216410.78 (123.55) & 797734.01 (125.96) \\
\hline $\begin{array}{l}\text { Schizophrenia or other } \\
\text { psychotic illness }\end{array}$ & 33300.65 (240.21) & 31727.58 (268.27) & 34052.58 (371.61) & 38689.78 (371.61) & $137770.58(240.21)$ \\
\hline Intentional self-harm & 5948.42 (251.69) & 5410.28 (374.74) & 8471.97 (439.54) & 7914.62 (485.07) & 27745.29 (348.70) \\
\hline $\begin{array}{l}\text { Toxic effects of } \\
\text { nonmedicinal substances }\end{array}$ & 103433.58 (212.80) & 112533.06 (246.11) & 126745.38 (268.02) & 162777.20 (268.02) & 505489.22 (268.02) \\
\hline All diagnoses & 761633.80 (212.80) & 800235.31 (246.11) & 977334.00 (268.02) & 1011673.21 (268.02) & 3550876.32 (244.51) \\
\hline
\end{tabular}


supported by the Alberta Heritage Foundation for Medical Research as a Health Scholar.

This study is based in part on data provided by Alberta Health and Wellness. The interpretation and conclusions contained herein are those of the researchers and do not necessarily represent the view of the Government of Alberta. Neither the Government of Alberta nor Alberta Health and Wellness express any opinion in relation to this study.

\section{REFERENCES}

1. Christodulu KV, Lichenstein R, Weist M, et al. Psychiatric emergencies in children. Pediatr Emerg Care 2002;18:268-70.

2. Guinto-Ocampo H, Molczan K, Selbst S. The epidemiology of mental health emergencies presenting to pediatric emergency departments [abstract]. Pediatric Academic Societies 2006;59:112.

3. Goldstein AB, Horwitz SM. Child and adolescent psychiatric emergencies in nonsuicide-specific samples: the state of the research literature. Pediatr Emerg Care 2006;22:379-84.

4. American Academy of Pediatrics; American College of Emergency Physicians, Dolan MA, Mace SE. Pediatric mental health emergencies in the emergency medical services system. Ann Emerg Med 2006;48:484-6.

5. Reder S, Quan L. Emergency mental health care for youth in Washington State. Pediatr Emerg Care 2004;20:742-8.

6. Santiago LI, Tunik MG, Foltin GL, et al. Children requiring psychiatric consultation in the pediatric emergency department. Pediatr Emerg Care 2006;22:85-9.

7. American Academy of Pediatrics, Committee on Pediatric Emergency Medicine. Pediatric mental health emergencies in the emergency medical services system. Pediatrics 2006;118:1764-7.

8. Parker KC, Roberts N, Williams C, et al. Urgent adolescent psychiatric consultation: from the accident and emergency department to inpatient adolescent psychiatry. I Adolesc 2003;26:283-93.

9. Smith DH, Hadorn DC. Lining up for children's mental health services: a tool for prioritizing waiting lists. $7 \mathrm{Am}$ Acad Child Adolesc Psychiatry 2002;41:367-77.

10. Kirby MJL, Keon WJ. Out of the shadows at last: transforming mental health, mental illness and addiction services in Canada. Ottawa (ON): Standing Senate Committee on Social Affairs, Science \& Technology; 2006.

11. Offord DR, Boyle MH, Szatmari P, et al. Ontario child health study II: six-month prevalence of disorder and rates of service utilization. Arch Gen Psychiatry 1987;44:832-6.

12. Offord DR, Boyle MH, Fleming JE, et al. Ontario child health study: summary of the selected results. Can J Psychiatry 1989;34:483-91.

13. Shah MV, Amato CS, John AR, et al. Emergency department trends for pediatric and pediatric psychiatric visits. Pediatr Emerg Care 2006;22:685-6.

14. Sills MR, Bland SD. Summary statistics for pediatric psychiatric visits to US Emergency Departments, 1993-1999. Pediatrics 2002;110:1-5.

15. World Health Organization. International statistical classification of diseases and related bealth problems, tenth edition). Available: www.who.int/classifications/icd/en/ (accessed 2009 Aug 6).

16. 2005 ACCS manual. Edmonton (AB): Alberta Health and Wellness; 2005.

17. Murray M, Bullard M. Grafstein E.; CTAS and CEDrosoph Inf Serv National Working Groups. Revisions to the Canadian Emergency Department Triage and Acuity Scale Implementation Guidelines. CJEM 2004;6:421-7.

18. Beveridge R, Clarke B, Janes L, et al. Canadian Emergency Department Triage and Acuity Scale: implementation guidelines. CJEM. 1999; 1(3 Suppl).

19. 1996 census dictionary. Ottawa (ON): Statistics Canada. 1999.

20. Terminology. Ottawa (ON): Indian and Northern Affairs Canada; 2003. Available: www.ainc-inac.gc.ca/ai/mr/is/tlneng.asp (accessed 2009 Aug 6).

21. Kunz FM, French MT, Bazargan-Hejazi S. Cost-effectiveness analysis of a brief intervention delivered to problem drinkers presenting at an inner-city hospital emergency department. I Stud Alcobol 2004;65:363-70.

22. Mancuso D, Nordlund DJ, Felver BEM. Chemical dependency treatment reduces emergency room costs and visits. Olympia (WA): Washington State DSHS, Research and Data Analysis Division; 2004.

23. Baren JM, Mace SE, Hendry PL, et al. Children's mental health emergencies - Part 1. Challenges in care: definition of the problem, barriers to care, screening, advocacy, and resources. Pediatr Emerg Care 2008;24:399-408.

24. Goldstein AB, Frosch E, Davarya S, et al. Factors associated with a six-month return to emergency services among child and adolescent psychiatric patients. Psychiatr Serv 2007;58: 1489-92.

25. Canadian Institutes of Health Information. Canadian classification of bealth interventions (vol. 4). Ottawa (ON): The Institutes; 2006.

Correspondence to: Dr. Amanda Newton, Department of Pediatrics, Faculty of Medicine and Dentistry, \#8213 Aberhart Centre One, 11402 University Ave., Edmonton AB T6G 2J3; mandi.newton@ualberta.ca 